\title{
Mudanças sociais e o trabalho docente de professores de Educação Física na escola: estudo a partir de histórias de vida
}

\author{
Elisandro Schultz, Wittizorecki* \\ Vicente Molina Neto ${ }^{* *}$ \\ Fabiano Bossle $e^{* * *}$
}

\begin{abstract}
Resumo: O presente estudo tratou de identificar quais mudanças sociais influenciam o trabalho docente do professorado de Educação Física na escola e, assim, compreender como esses professores experimentam tais mudanças, produzindo respostas e enfrentamentos às demandas sociais, culturais e educacionais na comunidade escolar em que atuam. Metodologicamente, utilizamos histórias de vida de seis docentes de Educação Física da Rede Municipal de Ensino de Porto Alegre/RS, de modo a construir com estes professores, compreensões e relações entre seus percursos pessoais e profissionais e o processo de mudanças sociais que vivemos.
\end{abstract}

Palavras-chave: Mudanças sociais. Professores de Educação Física. Histórias de Vida

Este trabalho relata parte dos achados de uma pesquisa ${ }^{1}$ que buscou compreender, através de seis histórias de vida de professores de Educação Física da Rede Municipal de Ensino de Porto Alegre (RMEPOA), que mudanças sociais influenciam o seu trabalho docente na escola e, como esses professores experimentam tais mudanças.

\footnotetext{
"Professor Adjunto da ESEF/UFRGS. E-mail: elisandro.wittizorecki@ufrgs.br

"Professor Titular da ESEF/UFRGS. E-mail: vicente.neto@ufrgs.br

"'Professor Adjunto da ESEF/UFRGS. E-mail: fabiano.bossle@ufrgs.br
}

'Trata-se de um recorte da tese de doutorado intitulada "Mudanças sociais e o trabalho docente do professorado de Educação Física na escola de Ensino Fundamental: um estudo na Rede Municipal de Ensino de Porto Alegre", apresentada no Programa de Pós-Graduação em Ciências do Movimento Humano da Universidade Federal do Rio Grande do Sul. 
Partimos do entendimento de que um problema de pesquisa não existe por si só. O pesquisador é que problematiza a realidade através de uma postura curiosa, insatisfeita, questionante, ouvinte, reflexiva, que busca ampliar seu grau de entendimento sobre o que considera ainda pouco compreensível, que forma/conforma/deforma o problema de pesquisa. Nesse sentido, o ponto de partida de nossas indagações nasce de um problema que escolas e professores enfrentam atualmente: a necessidade de repensarem a si próprios diante de mudanças sociais que, nos parece, têm levado a importantes mudanças no sentido de seu trabalho.

Neste percurso de transitar do tema de interesse à construção do problema de investigação, entendemos ser relevante contextualizar os marcos teóricos que orientaram nosso estudo. Partimos das indicações de Lincoln e Guba (2006), que convidam o pesquisador a localizar suas pretensões e pressupostos, respondendo três grandes questões:

a) Como concebemos a forma e a natureza da realidade? (pergunta ontológica);

b) Qual é natureza da relação entre o pesquisador - ou possível conhecedor - e o que pode ser conhecido? (pergunta epistemológica);

c) Como pode o investigador chegar a conhecer aquilo que crê que pode ser conhecido e estudado? (pergunta metodológica).

Do ponto de vista ontológico, e levando em conta os problemas da educação e da docência, entendemos que é possível aproximarse de uma compreensão acerca de suas dinâmicas, de suas contradições e conflitos, considerando as singularidades, as culturas e as histórias dos sujeitos e instituições nelas envolvidos. Partilhamos da noção de que constituímos parte desta realidade que buscamos pesquisar (HAMMERSLEY; ATKINSON, 2001) e compreender, e que ao fazê-lo, também nos compreendemos e nos reconstruímos. Em outras palavras, encaramos a realidade de modo dinâmico, construído e representado pelos significados da ação humana.

Do ponto de vista epistemológico, consideramos que neste estudo, tão importante quanto compreender o que os docentes fazem 
ou vêm podendo fazer, é compreender com² $^{2}$ eles o que reflexionam e como valoram sua experiência. Ou seja, assumimos uma posição que busca deslizar do lugar de pesquisador prescritivo para uma noção de sujeito presente na investigação, dialogante, aprendente, e que ao pesquisar com o outro, se reconstrói, se reconhece e cria espaços para que o outro também o faça.

Do ponto de vista metodológico, entendemos ser mais coerente adotar uma perspectiva metodológica que dê conta do diálogo entre pesquisadores e docentes, que revise permanentemente as relações de poder entre estes e que permita reconstruir com os professores as relações entre seus percursos pessoais e profissionais, visibilizando a reflexão e à valoração que fazem acerca de suas experiências.

A seguir, apresentamos alguns referenciais teóricos que entendemos contribuir na tarefa de mapear mudanças sociais que se apresentam dilemáticas à docência e nos permitiram construir o problema de pesquisa.

\section{MUdANÇAS SOCIAIS E A DOCÊNCIA}

Wittizorecki e Molina Neto (2005) argumentam que os professores de Educação Física se encontram perplexos frente a algumas mudanças sociais e culturais que têm produzido um distanciamento entre o que a área tradicionalmente construiu como sua tarefa primordial na escola - ensino-aprendizagem das manifestações da cultura corporal do movimento humano - e demandas de outras ordens, como a gestão de conflitos e o atendimento de tarefas advindas de inovações curriculares. É possível pensar que esses acontecimentos refletem parte de um processo mais complexo, onde tem ocorrido uma mudança nos padrões de socialização e dos papéis da escola e dos professores (PÉREZ GÓMEZ, 1998).

Essa ideia pode ser ampliada com a descrição de Pérez Gómez (1998) ao narrar a sensação de perplexidade vivida por professores

${ }^{2}$ Grifo nosso para destacar um modo de investigação que não se dá na direção de pesquisar os professores e suas práticas pedagógicas, mas com estes e valorizando sua perspectiva.

Movimento, Porto Alegre, v. 18, n. 01, p. 149-169, jan/mar de 2012. 
nos atuais tempos, em virtude da transformação dos fundamentos que orientavam e legitimavam sua prática. Fundamentos estes que a escola, como produção do Iluminismo, incorporou ao ser engendrada como espaço e veículo de um ideal de civilização, de um ideal de ensino e transmissão do conhecimento, de um ideal de conformação do sujeito humano; sendo os docentes, os agentes desta maquinaria.

Hagemeyer (2004) argumenta que na atualidade, os problemas político-econômicos se aliam à vertiginosa evolução científica e tecnológica, refletindo-se em "mudanças nas formas de ser e viver dos homens em todos os níveis, desconcertando a quem tem a profissão de ensinar/formar crianças e adolescentes" (p. 68). Características como a ampliação do papel do professor e a diminuição da responsabilidade familiar sobre a educação dos jovens e crianças; a revolução eletrônica e o intenso crescimento e difusão dos meios de comunicação como instrumentos também pedagógicos (cujos impactos no alunado se dão de forma tão ou mais significativa, quanto à intervenção dos docentes); a exaltação de valores como o individualismo, a competitividade, a rentabilidade e a obsessão pela eficiência são elementos que contribuem para a configuração de uma perplexidade docente, frente a uma sociedade em constantes transformações.

Hargreaves (1996) ajuda a entender esse quadro de tensões e mudanças, pontuando que o problema fundamental está na confrontação que se produz entre duas forças poderosas. De um lado, o mundo cada vez mais pós-industrial e pós-moderno, caracterizado por transformações aceleradas, por uma intensa compressão de tempo e espaço, diversidade cultural, complexidade tecnológica, insegurança nacional e incerteza frente à ciência. De outro, um cenário em que o sistema escolar modernista, monolítico, segue buscando finalidades anacrônicas, sustentada em estruturas opacas e inflexíveis. Para o autor, a modernidade pode ser caracterizada por uma condição social impulsionada pela fé iluminista no progresso cientifico racional, no triunfo da tecnologia sobre a natureza e na capacidade de controlar e melhorar a condição humana mediante a aplicação desta bagagem de conhecimentos e domínio científicos e tecnológicos à reforma social. 
Ainda Hargreaves (2003), sustenta que grande parte das escolas orientada em princípios "modernos, e inclusive pré-modernos, da fábrica e do monastério" (2003, p. 32), governada por relógios e campainhas, organizadas em níveis e turmas, e ensinando conhecimentos memorizáveis com formas de avaliação tradicionais, persistem com esse "modernismo ${ }^{3 "}$ convencional através de ações profissionais e administrativas arraigadas na certeza das tradições e da certeza de suas próprias experiências e rotinas, ao invés de se dirigirem as preocupações dos estudantes, das famílias e das comunidades. Esta parece ser uma consideração dilemática importante à docência, na medida em que o autor identifica as atuais configurações sociais calcadas em valores e finalidades que, provavelmente, é bastante distinto dos parâmetros em que muitos professores construíram sua cultura docente.

Hobsbawn (1995), ao analisar as principais transformações do século XX, aponta a insegurança traumática produzida entre os sujeitos quando velhas convenções de idéias e comportamentos caem ou quando perdem suas justificativas. Fatores que levam as instituições e seus atores - como as escolas e os professores - a um certo quadro de desconcerto e incerteza (SANCHO GIL; HERNÁNDEZ, 2004), tendo assim que reelaborar seus papéis sociais e pedagógicos.

Abordando a questão das mudanças no mundo do trabalho, Sennett (2003) apresenta uma análise sobre as novas características do trabalho (notadamente a partir do contexto norte-americano) orientado por uma nova economia, marcada pela globalização e flexibilidade. De acordo com esse autor, se exige dos trabalhadores um comportamento ágil e disponibilidade as mudanças de tarefa e de ocupações, desfazendo uma segurança e estabilidades até então vivenciadas. Projetos em curto prazo, transitoriedade, remodelações, inovações, cooperação superficial entre os pares no trabalho parecem ser palavras chaves nesses novos ordenamentos. Acrescenta o autor que essa mudança, e aqui residem os efeitos mais brutais, acaba por

${ }^{3}$ Destaque entre aspas do próprio autor.

Movimento, Porto Alegre, v. 18, n. 01, p. 149-169, jan/mar de 2012. 
debilitar, por corroer valores adotados pelas pessoas no âmbito de seu trabalho e fora dele, como a lealdade, a confiança, a fidelidade, o estabelecimento de objetivos e compromissos recíprocos em longo prazo e a solidificação de laços emocionais duradouros.

A argumentação de Bauman (2001, p. 160) pode contribuir para a discussão quando declara que "[...] o trabalho perdeu a centralidade que se the atribuía na galáxia dos valores dominantes na era da modernidade sólida e do capitalismo pesado. O trabalho não pode mais oferecer o eixo seguro em torno do qual envolver e fixar autodefinições, identidades e projetos de vida." Este autor complementa afirmando que, junto com outras atividades, o trabalho adquiriu uma significação principalmente estética. Em sua análise, o trabalho muito mais tenderia a satisfação por si mesmo e em si mesmo, não podendo ser avaliado exclusivamente por seus efeitos específicos ou objetivos "maiores" a que se proporia, dentro de um projeto de humanidade.

Bauman (2001) se utiliza da metáfora dos líquidos para descrever as condições atuais da vida social e política: líquida e muito mais dinâmica que a modernidade "sólida" que superou. Para o autor, a fluidez ou liquidez são "metáforas adequadas quando queremos captar a natureza da presente fase, nova de muitas maneiras, na história da modernidade" (BAUMAN, 2001, p. 9), já que os líquidos por não manterem sua forma com facilidade, não fixam o espaço, nem prendem o tempo. Ou seja, essa ideia fluidez está associada à mobilidade e a inconstância, marcadores importantes na obra deste autor quando busca contextualizar a contemporaneidade. Essa inconstância e mobilidade estão manifestas nas múltiplas experimentações possíveis dos tempos e espaços pelos sujeitos, nas flexibilizações das rotinas nas organizações, na precarização e desconfiança dos laços humanos, na ênfase às práticas individualistas e individualizadoras.

É importante destacar que Bauman (2001) acrescenta uma outra condição importante ao argumento das incertezas na contemporaneidade: a individualização. Para ele, a vida de trabalho sempre foi cheia de incertezas, no entanto, a incerteza de hoje é de 
um tipo completamente novo, marcada pela poderosa força individualizadora. Diz o autor que "os medos, ansiedades e angústias contemporâneos são feitos para serem sofridos em solidão" (BAUMAN, 2001, p. 170), fato que vem no mesmo rol de outras características que apresenta acerca dos laços humanos no mundo fluído e líquido que vivemos. Precariedade dos laços afetivos, vulnerabilidade das relações e falta de garantias (de sobrevivência, de posição) reaparecem em sua argumentação como marcas sociais da contemporaneidade.

Se por um lado dispomos de condições de prolongamento e qualificação da vida, nos seus mais diferentes contextos, soa estranho que ainda soframos com as mazelas da fome, do analfabetismo, da violência infantil e familiar, da exclusão social, do desemprego. No contexto e no entorno das escolas da RMEPOA, estas situações estão muito presentes. A escola e os docentes não são blindados à concretude da realidade onde se inserem: respiram e medeiam situações vinculadas a esses fenômenos, que exigem seus posicionamentos, quer no âmbito formal da aula, quer fora dela.

Diehl e Molina Neto (2010), por exemplo, em pesquisa com professores de Educação Física na RMEPOA, concluíram que, entre outros elementos, novos arranjos geográficos de moradia, bem como o fluxo migratório dos estudantes e suas famílias entre os bairros da cidade interfere diretamente na organização escolar, já que "os sujeitos, ao mudarem de ambiente, levam consigo os costumes e referências culturais do local de origem" (idem, p. 256).

A partir dessas argumentações, a questão de pesquisa construída e que conduziu o estudo foi: na perspectiva de professores de Educação Física da RMEPOA, quais mudanças sociais influenciam o seu trabalho docente na escola? Como experimentam estas mudanças, produzindo respostas e enfrentamentos às demandas sociais, culturais e educacionais na comunidade escolar em que atuam? 


\section{DeCisões Metodológicas}

Por acreditarmos numa forma colaborativa de produzir conhecimento com o professorado, valorizando suas experiências vividas, procuramos dar conta do problema de pesquisa, investindo em um estudo que pudesse construir e reconstruir com os docentes, suas histórias de vida profissionais. Bauer e Gaskell (2002) afirmam que parece existir em todas as formas de vida humana, uma necessidade de contar; contar histórias parece ser uma forma elementar de comunicação humana. Argumento também compartido por Connelly e Clandinin (1995) ao defenderem que somos organismos que, individual e socialmente, vivemos vidas relatadas.

Goodson (2004) comenta que este tipo de trabalho tem como objetivo desenvolver estratégias para que os professores analisem e reflexionem sobre sua vida e seu trabalho de tal modo que possam dar respostas mais profundas e poderosas frente à complexidade do mundo socialmente construído da educação.

Tanto Nóvoa (1995) como Bueno (2002) concordam que a partir dos anos 80, há um crescimento na ênfase de pesquisas sobre formação do professorado, a partir de estudos sobre as vidas dos professores, suas carreiras, percursos profissionais e autobiografias docentes. Tal tendência se acentua porque ganha visibilidade um momento nas teorizações e pesquisas educacionais, onde se concebe que a vida do profissional é, antes de qualquer coisa, a vida da pessoa que trabalha como professor. No âmbito brasileiro, destacamos estudos recentes que investiram nessa perspectiva de estudos biográfico-narrativos com docentes, como Folle et al (2009), Santos, Bracht e Almeida (2009), Bossle e Molina Neto (2009), Machado et al (2010) e Figueiredo (2010).

Assim como outras perspectivas que procuram aumentar a visibilidade dos professores e reconhecer o direito a falar e estar representado (BOLÍVAR; DOMINGO; FERNÁNDEZ, 2001), entendemos que as histórias de vida avançam de uma perspectiva exclusiva de investigação, para atuar no binômio investigação/ formação (OLIVEIRA, 2006a; JOSSO, 2004), constituindo espaços 
de reflexão, em que "mediante conteúdos de suas histórias de vida, possa participar de uma pesquisa com incidência em seu processo de formação" (OLIVEIRA, 2006a, p. 171).

No entanto, Goodson (2004) chama a atenção para o fato de que conferir protagonismo ao professorado no sentido de narrar e compreender seus percursos, não lhe garante necessariamente autoridade e autonomia, sobretudo no âmbito das políticas curriculares e administrativas. Que contribuição poderia então, trazer um conhecimento dessa natureza? No que consistiria sua potencialidade investigativa e educativa? Sobretudo nos atuais tempos, em que as constantes reformas legislativas, administrativas e estruturais ganharam notoriedade como as autênticas alavancas de transformação da educação - levando a um entendimento de que é implementando outros marcos legais que se poderia contornar os problemas educativos - entendemos que a potência desta forma de pesquisar reside na possibilidade do docente reposicionar seu desejo, de identificar o que lhe move e o que lhe impossibilita, de reconhecer também em si e não somente fora de si, as possibilidades de recriação, de reinvenção, de negação, de resistência, das condições e circunstâncias que lhe ajudam ou lhe inviabilizam.

Nesse sentido, Goodson (2004) recomenda que no processo analítico e investigativo, se possa considerar os professores como sujeitos ativos na construção de sua própria história, tendo a oportunidade de também teorizar sobre a mesma. Com isso, é possível questionar os limites entre quem "investiga" e é "investigado". Quem dirige a pesquisa? Quem se constitui no autor da pesquisa? Tais questões nos levaram a buscar uma relação colaborativa no trabalho de campo e que exigia repensar as relações de poder e autoria a todo o momento da investigação.

Pesquisar com histórias de vida busca romper com uma racionalidade instrumental de concepção de formação de professores e investir numa compreensão contextual e complexa dos processos educativos onde as valorações pessoais, emocionais, técnicas e políticas acerca desses, ganham especial importância. Nessa linha, Oliveira (2006b, p. 55) pontua que: 
Esta tentativa de entender como nos produzimos no que somos hoje, é uma experiência que nos afasta de concepções que se dispõem a prescrever o que os outros devem ser. Ao contrário, nos propomos a conhecer como os outros puderam ser, a partir de determinados contextos sócio-culturais.

Após aprovação pelo Comitê de Ética da Universidade Federal do Rio Grande do Sul, o trabalho de campo da pesquisa foi realizado de maio de 2008 a fevereiro de 2009. A representatividade tipológica dos participantes procurou contemplar:

a) professoras e professores de Educação Física;

b) docentes de distintas escolas;

c) docentes com diferentes tempos de experiência escolar (até 15 anos, entre 15 e 25 anos, com mais de 25 anos).

Aceitaram participar como colaboradores, duas professoras e quatro professores de Educação Física. No quadro seguinte, apresentamos alguns dados acerca de sua formação, experiência e contexto laboral, no momento do trabalho de campo:

\begin{tabular}{|c|c|c|c|c|}
\hline Nome & $\begin{array}{c}\text { Ano e Local de } \\
\text { Formação } \\
\text { Inicial }\end{array}$ & Âmbito de Formação & $\begin{array}{c}\text { Regime de } \\
\text { Traba lho na } \\
\text { RMEPOA }\end{array}$ & $\begin{array}{c}\text { Tempo de experiência } \\
\text { docente Escolar }\end{array}$ \\
\hline Cláudia & $1990-$ UFSM & Mestrado & $20 \mathrm{~h}$ & 13 anos \\
\hline Sara & $1985-$ IPA & Especialização & $40 \mathrm{~h}$ & 17 anos \\
\hline Artur & $1977-$ UFRGS & Especialização & $30 \mathrm{~h}$ & 26 anos \\
\hline Julio & $1978-$ UFRGS & Especialização & $40 \mathrm{~h}$ & 19 anos \\
\hline Henrique & $1980-$ UFRGS & Especialização & $20 \mathrm{~h}$ & 19 anos \\
\hline Roberto & $1988-$ UFRGS & Especialização & $20 \mathrm{~h}$ & \\
\hline
\end{tabular}

Fonte: Autores

Quadro 1 - Colaboradores do estudo

Todos os nomes dos colaboradores, bem como das escolas, conforme previa o Termo de Consentimento Livre e Esclarecido, foram substituídos por nomes fictícios, de modo a preservar o sigilo de suas identidades.

Como instrumentos de coleta de informações, utilizamos diário de campo, análise de documentos e entrevistas. As entrevistas foram 
realizadas individualmente, gravadas (com o prévio consentimento dos participantes), transcritas e posteriormente devolvidas aos respectivos entrevistados para que validassem o conteúdo das mesmas e avaliassem a fidedignidade do que foi registrado em suas narrativas.

Numa primeira etapa de apresentação e análise das informações, construímos seis textos, cujo estilo narrativo procurou contar as histórias de vida de cada um dos docentes; alternando entre contribuições do colaborador e explicações e interpretações dos pesquisadores. A partir das histórias, construímos categorias de análise de modo a aprofundar a discussão das informações obtidas.

\section{MERGULHANDO NAS HISTÓRIAS DE VIDA DOS PROFESSORES}

O estudo nos permitiu aprender que as principais mudanças narradas pelo professorado e que impactam em seu trabalho tinham que ver com: a) papéis da escola na atualidade; b) reestruturações curriculares e seus efeitos na RMEPOA; c) lugares do trabalho na vida dos docentes; d) efeitos da globalização no trabalho docente.

Por razões de exiguidade de espaço e pelas características de um artigo, optamos por examinar com mais detalhamento a terceira categoria - lugares do trabalho na vida dos docentes - e suas implicações no problema de pesquisa, apresentando alguns fragmentos das histórias de vida dos professores e as análises construídas.

Com a opção metodológica de construir histórias de vida de professores, pudemos aprofundar uma compreensão dos processos através dos quais essas pessoas se formam e como lêem seu percurso laboral nesse momento de suas vidas. Aprendemos com os professores a enorme multiplicidade de experiências que cada um vive, de onde constrói lições, acumula preocupações, improvisa soluções e se reinventa permanentemente. Assim, durante o trabalho de campo, procuramos alimentar um vínculo com os colaboradores e um caminho metodológico que pudesse valorizar o que Josso (2004) sugere de pesquisa-formação. 
Nesse sentido, a professora Sara ao relatar a leitura que tem de seu percurso, reconhece o processo de conhecimento de si e autoformação que viveu a partir de seu trabalho, explicando como essas aprendizagens colaboraram para que pudesse articular seu itinerário de forma mais serena e "confortável". Para Sara, reconhecer sua própria impotência frente a tantas demandas escolares e admitir a condição de incompletude, revelou-se um processo duro e difícil, porém de necessária realização, pois lhe permitiu encarar o trabalho com menor sofrimento e maior clareza de suas possibilidades:

Acho que eu amadureci, eu fui obrigada a estudar, a me conhecer melhor assim, a ser menos prepotente porque eu acho que eu era mais [...], a me dar conta de que..., porque tu achas que o teu trabalho é que vai resolver a situação de todo mundo. De que é um processo mesmo, pena que tenha gerado assim até o momento mais frustração do que realização. Então assim, me descobri professora, aprendi a me aceitar também assim com as minhas limitações, isso é uma coisa importante que é difícil aceitar, que tu és limitada. Foi muito difícil para mim essa coisa de dizer assim: olha, não consegui! Não dei conta desse grupo aí!

Desde essa fala, pensamos que ao lhe conferir protagonismo e dar-lhe suporte a se autorizar a dizer de si, esse estudo pode evocar que outros professores possam examinar seus percursos, reconhecer suas singularidades, "para que surja um ser que aprenda a identificar e combinar constrangimentos e margens de liberdade. Transformar a vida socioculturalmente programada numa obra inédita a construir, guiada por um aumento de lucidez, tal é o objetivo central que oferece a transformação da abordagem Histórias de Vida" (JOSSO, 2004, p. 58-59, grifo do autor).

A professora Cláudia diz de si de forma semelhante a professora Sara, ao identificar a limitação do alcance de seu trabalho:

$\mathrm{Eu}$ acredito que essa questão pra mim é central: conhecer-se, compreender-se, possibilitar que o aluno conheça mais de si mesmo a partir das práticas 
do corpo é uma conquista. E é um trabalho de formiguinha, que eu não posso ficar esperando que eu vou atingir a todos.

Então a gente fica empolgada, olhando na minha trajetória são pequenas conquistas, de conseguir colocar as coisas que eu acredito em ação, de produzir significado em algumas coisas que eu acredito [...], apesar de todas essas coisas, creio que eu tenho conquistado um certo espaço e está me possibilitando estar mais afinada com o que eu penso e o que eu estou fazendo. A distância entre o que eu pensava e que eu fazia era maior, agora não.

Bauman (2001, p. 157) argumenta que o trabalho foi elevado ao patamar de principal valor nos tempos modernos, principalmente pela "moderna ambição de submeter, encilhar e colonizar o futuro, a fim de substituir o caos pela ordem e a contingência pela previsível (e portanto controlável) sequência dos eventos." Adverte o autor que ao trabalho foram atribuídos muitas virtudes e efeitos benéficos, como o aumento da riqueza e diminuição da miséria, além de sua "suposta contribuição para o estabelecimento da ordem, para o ato histórico de colocar a espécie humana no comando de seu próprio destino" (BAUMAN, 2001). A narrativa da professora Cláudia nos convida a encarar o trabalho docente distanciando-se desta perspectiva e aproximando-se de uma compreensão deste, cujas repercussões produzem sentido e se instauram em pequenos episódios do cotidiano escolar.

A partir dessas narrativas é possível pensar que essas professoras assumem o caráter limitado do trabalho docente, cuja satisfação parece advir mais dos pequenos avanços e conquistas do cotidiano, que de efeitos maiores tradicionalmente alardeados pela metanarrativa ${ }^{4}$ tradicional da educação escolar. Tal idéia se aproxima ao que argumenta Bauman (2001), ao afirmar que o trabalho ganha nos tempos atuais uma significação principalmente estética, onde se espera que possa ser satisfatório em si e por si mesmo.

\footnotetext{
${ }^{4}$ Tradicionalmente se entendeu na modernidade que a escolarização seria um instrumento de ascensão social.
}

Vovimento, Porto Alegre, v. 18, n. 01, p. 149-169, jan/mar de 2012. 
O contato com os colaboradores nos permitiu pensar que os docentes parecem rejeitar uma gratificação que remeta a uma noção "vocacional". A professora Sara, por exemplo, faz uma análise interessante do trabalho que desempenha como professora de Educação Física - em função do cargo a que prestou concurso - e do trabalho que efetivamente lhe investe prazer: aulas de dança. Nesse sentido, ao se referir as aulas que ministra de basquetebol, Sara narra:

E isso é uma coisa muito clara, eu não sei demonstrar, eu sei a teoria todinha, mas na hora que eu vou demonstrar os alunos percebem que eu não domino aquilo, e fica difícil de ensinar. Meus alunos não progridem como eu gostaria, como é na Dança.

No decorrer do trabalho de campo, dialogamos algumas vezes sobre o sentido no trabalho nas nossas vidas. Em dado momento, Sara nos comentou "eu quero é ser feliz no meu trabalho", revelando sua pulsão de encontrar alguma satisfação no trabalho. Ainda pensando nos lugares que o trabalho vem ocupando para os docentes colaboradores, o professor Henrique chama atenção na próxima fala para a condição permanente de revisar-se como uma marca que o trabalho docente lhe provocou. Ele se vê como um sujeito que enxerga a necessidade de se ler, de se revisar, de ler o mundo, de ler os sujeitos e com isso estar aberto a transformar-se junto com as mudanças desses últimos. Algo que, se por um lado lhe possibilita uma posição dinâmica e de viabilidade frente às mudanças sociais, por outro lhe coloca no âmago da instabilidade e vulnerabilidade que a modernidade líquida (BAUMAN, 2001) parece oferecer.

Nessa minha construção eu estou sempre muito aberto, ela tem que ser revista, ser repensada, reconstruída e, ao mesmo tempo, eu me sinto seguro pra dizer "olha, estou com esta proposta, estou acreditando nela por isso, por isso e por aquilo, estou sustentando ela na minha caminhada, nas minhas experiências, no meu estudo, nas contribuições destes e daqueles, eu também estou sempre aberto a "me equivoquei neste aspecto" e estou revisando. Acho que desde o início fui sempre 
muito aberto a isso, e estar aberto a isso me dá muita tranqüilidade de fazer, de apresentar uma proposta determinada.

Por outro lado, o professor Júlio alerta que essa condição de revisar-se e de ler o mundo nem sempre pode ser fácil a todos os professores, uma vez que a intensificação do trabalho docente largamente discutida por Hargreaves (1996) - pode gerar um isolamento dos sujeitos e uma certa automatização de suas ações. Júlio mesmo, por exemplo, trabalha como professor na RMEPOA com regime de 40h/semanais e ainda atua outras 20h/semanais na rede pública estadual gaúcha.

A maioria dos professores em razão ao salário de trabalho que recebem, tem que trabalhar 60 horas, ou seja, está comprometido nos três turnos pelo trabalho. Mal sai de um lugar, já está correndo para ir para o outro. [...] então este distanciamento fez com que os professores também se distanciassem das causas sociais, na maioria das escolas os professores transitam pela escola e os problemas daquela comunidade escolar não são bem vistos, não são bem enxergados pelos professores devido principalmente a essa aceleração.

O professor Júlio revela uma importante consequência das mudanças sociais que entende estar impactando nos professores: com a intensificação do trabalho e a aceleração na noção de tempo, gera-se uma certa dificuldade na leitura das características e demandas de seu grupo de trabalho, de sua escola, da comunidade onde atua e, por sua vez, do mundo em que vive. É relevante destacar que o trabalho docente tem se constituído num trabalho que demanda profundamente a dimensão emocional dos professores, constituindo tema já bastante tratado na bibliografia da área, descritos em fenômenos, como por exemplo, mal-estar docente (ESTEVE, 1995) e síndrome do esgotamento profissional (SANTINI; MOLINA NETO, 2005).

A pesquisa com histórias de vida nos levou a compreender as idiossincrasias dos docentes colaboradores e os discursos de verdade desses sujeitos. Talvez mais relevante que "tratar" o mal-estar docente 
ou a síndrome de esgotamento dos professores, seja lhes conferir espaços e tempos que rompam a noção lógica de tempo, para que se autorizem a narrar, e com isso, possam deslizar para outros lugares que lhe permitam ler a si e seu trabalho de outro modo. Nas palavras de Josso (2004, p. 58):

O que está em jogo nesse conhecimento de si mesmo não é apenas compreender como nos formamos por meio de um conjunto de experiências, ao longo de nossa vida, mas sim tomar consciência de que este reconhecimento de si mesmo como sujeito, mais ou menos ativo ou passivo segundo as circunstâncias, permite à pessoa, daí em diante, encarar o seu itinerário de vida, os seus investimentos e os seus objetivos na base de uma auto-orientação possível, que articule de uma forma mais consciente as suas heranças, as suas experiências formadoras, os seus grupos de convívio, as suas valorizações, os seus desejos e o seu imaginário nas oportunidades socioculturais que soube [e pode] aproveitar, criar e explorar.

Recorro novamente às narrativas da professora Sara, ao falar de sua chegada à primeira escola da RMEPOA. Seria viável "tratar" seu mal-estar? Como reposicionar seu desejo frente a um contexto jamais experienciado antes?

Na Escola Jacarandá de manhã eu atendia os pequenos. É uma pobreza, não sei hoje como está, mas na Restinga Velha tinha criança que morava ainda em caverna, morava no meio do morro que não era casa era um buraco no meio do morro. Então na hora da merenda não podia dar o que sobrava, mas a família ficava na porta, ficava a família, ficava os cachorros, ficava os irmãos, e eu ainda não tinha me acostumado mesmo depois assim de Alvorada. Nessa época eu fazia terapia e eu me lembro que a minha terapeuta dizia: - Olha, tu tem que pedir uma transferência porque não é uma questão de adaptação. Tu não vai te adaptar. Eu tava deprimida, eu tava passando mal já, porque eu vomitava sempre. O motorista do ônibus me dizia assim: professora, tu tem que tomar um remédio! Mas não era uma questão de enjôo, era depressão, eu me sentia muito mal. 
Para Dejours (1992) a noção de sofrimento é central e implica um estado de luta do sujeito contra as forças que estão empurrando em direção à doença mental. Por outro lado, o autor afirma que é na organização do trabalho que se deve procurar essas forças. Entende por organização do trabalho não só a divisão do trabalho, isto é, a divisão de tarefas entre os operadores, os ritmos impostos e os modos operatórios prescritos, mas também, e, sobretudo, a divisão de tarefas, representada pelas hierarquias, as repartições de responsabilidade e os sistemas de controle.

Nesse caso, a solução encontrada pela professora foi pleitear uma transferência de escola onde pudesse realizar um trabalho que traduzisse seu desejo, que representasse reconhecimento e a possibilidade de trabalhar com aquilo que melhor entendia no momento: aulas de dança. Ao falar de sua mudança para a Escola Cipreste, a professora Sara diz que:

Eu estava vivendo uma outra realidade, de eu poder fazer os meus projetos, escrever, publicar, eu já tinha publicado o trabalho de uma releitura corporal que eu tinha feito do Acervo do Museu de Arte do Rio Grande do Sul, um trabalho todo de expressão corporal.

A partir das narrativas dos colaboradores, pudemos compreender que a metanarrativa da escolarização como "tábua de salvação" para as mazelas sociais e para o progresso da humanidade como processo contínuo e infinito parecem não fazer tanto sentido aos professores quanto as ações e reflexões desencadeadas em cada situação singular do cotidiano. Parece haver uma sensação de dúvida quanto a possibilidades definitivas e totalizadoras da educação escolar e muito do que dá sentido ao trabalho desses docentes é narrado pela humildade e pela potência de reconhecer suas limitações e anunciar seus avanços nas pequenas ações de suas aulas e relações na escola com os estudantes. 


\section{Considerações tRanstó́rias}

O longo período de trabalho de campo (dez meses) nos permitiu aprender que há uma necessidade dos professores falarem de si, do que vivenciam, do que sentem. As mudanças sociais, seus efeitos e experimentação figura como um dos temas candentes nas suas narrativas, entre outros tantas problematizações. Essa vontade de falar pode estar ligada a certa apreensão dos professores acerca de sua condição no mundo, onde narram uma fragilização e individualização dos laços entre os sujeitos na atualidade.

É possível pensar que tais mudanças têm impactado nas aulas dos professores, principalmente quando suas tarefas cedem lugar à necessidade de gerenciar conflitos gerados a partir do ambiente extraescolar, quando os docentes não se autorizam a exercer seu lugar e suas prerrogativas como tal, em função da fragilização da rede de apoio à docência que existe nas escolas. Os argumentos dos colaboradores nos permitiram entender que o trabalho docente - ou poderíamos dizer num trocadilho (dor)sente - tem absorvido e sentido o efeito de uma sociedade diversa, globalizada, acelerada, que idealizava a educação como salvadora da humanidade e ainda não encontrou respostas satisfatórias ou confortáveis para dar conta disso.

Longe de estabelecer normativas regulatórias ou um ato de vouyerismo frente às narrativas docentes, a pesquisa com histórias de vida revela-se como uma potencialidade para atuar no binômio investigação/formação, permitindo aos professores colaboradores e aos pesquisadores, uma ressignificação da vida vivida nas escolas. Concordando com Connelly e Clandinin (1995), pensamos que as histórias de vida de docentes podem contribuir para que se possa evocar outros docentes a se autorizarem a narrar suas histórias e que essas possam gozar igualmente de validez e força, ao conectar o particular e o geral, o detalhe e a globalidade de suas experiências. 


Social changes and work teaching of Physical
Education teachers in school: study from life
history
Abstract: This study aimed to understand social
changes which influence the teaching of teachers of
physical education at school and understand how
these teachers experience these changes, producing
responses to social demands and confrontations,
cultural and educational community school where they
work. Methodologically, we use the life stories of six
physical education teachers of municipal schools in
Porto Alegre/RS, in order to build with these teachers,
understandings and relationships between their
personal and professional trajectories and profound
process of social changes that have lived.
Keywords: Social changes. Physical Education
teachers. Life history.

Cambios sociales y el trabajo docente del profesorado de Educación Física en la escuela: estudio desde las historias de vida

Resumen: El presente estudio ha buscado comprender qué cambios sociales han influenciado el trabajo docente del profesorado de Educación Física en la escuela y, así, entender mejor cómo esos profesores han experimentado los cambios, reaccionando y produciendo respuestas a las demandas sociales, culturales y educacionales en la comunidad escolar dónde trabajan. Metodológicamente, hemos utilizado historias de vida de seis profesores de Educación Física de la Red Pública de Enseñanza del Ayuntamiento de Porto Alegre/ RS, para construir con estos profesores comprensiones y relaciones entre sus trayectos personales y profesionales y el profundo proceso de cambios sociales que hemos vivido.

Palabras-clave: Cambios sociales. Profesores de Educación Física. Historias de Vida

\section{REFERÊNCIAS}

BAUER, M.; JOVCHELOVITCH, S.. Entrevista Narrativa. In: BAUER, M. W.; GASKELL, G. Pesquisa qualitativa com texto, imagem e som: um manual prático. Petrópolis: Vozes, 2002.

BAUMAN, Z.. Modernidade líquida. Rio de Janeiro: Zahar, 2001.

BOLÍVAR, A.; DOMINGO, J.; FERNÁNDEZ; M.. La Investigación biográficonarrativa en educación. Madrid: La Muralla, 2001. 
BOSSLE, F.; MOLINA NETO, V. No "Olho do Furacão": uma autoetnografia em uma escola da Rede Municipal de Ensino de Porto Alegre. Revista Brasileira de Ciências do Esporte, Florianópolis, v. 31, p. 131-146, 2009.

BUENO, B.. O método autobiográfico e os estudos com histórias de vida de professores: a questão da subjetividade. Educação e Pesquisa, São Paulo, v. 28, n. 1, p. 11-30, jan./jun. 2002.

CONNELLY, M.; CLANDININ, J. Relatos de experiencia e investigación narrativa. In: LARROSA, J. Déjame que te cuente: ensayos sobre narrativa y educación. Barcelona: Laertes, 1995. p. 11-59.

DEJOURS, C.. Loucura do trabalho. São Paulo: Oboré, 1992.

DIEHL, V.; MOLINA NETO, V. Fluxo migratório e a ação pedagógica dos professores de Educação Física. Educação e Realidade, Porto Alegre, v. 35, p. 253-277, 2010.

ESTEVE, J. Mudanças sociais e função docente. In: NÓVOA, A. Profissão professor. Lisboa: Porto Celebra, 1995.

FIGUEIREDO, Z.. Experiências Profissionais, Identidades e Formação Docente em Educação Física. Revista Portuguesa de Educação, Minho, v. 23, p. 153-172, 2010.

FOLLE, A. et al. Construção da carreira docente em Educação Física: escolhas, trajetórias e perspectivas. Movimento, Porto Alegre, v. 15, n. 1, p. 25-49, jan./ mar., 2009.

GOODSON, I. (Org.). Historias de vida del profesorado. Barcelona: Octaedro, 2004.

HAGEMEYER, Regina Cely de Campos. Dilemas e desafios da função docente na sociedade atual: os sentidos da mudança. Educar em Revista, Curitiba, n. 24, p. 67-85, 2004.

HAMMERSLEY, M.; ATKINSON, P. Etnografía: métodos de investigación. Barcelona: Paidós, 2001.

HARGREAVES, A. Profesorado, cultura y postmodernidad: cambian los tiempos, cambia el profesorado. Madrid: Morata, 1996.

Enseñar el sociedad del conocimiento. Barcelona: Octaedro, 2003.

HOBSBAWN, E.. Era dos extremos: o breve século XX: 1914-1991. São Paulo: Companhia das Letras, 1995.

JOSSO, M.. Experiências de vida e formação. São Paulo: Cortez, 2004.

LINCOLN, Y.; GUBA, E.. Controvérsias paradigmáticas, contradições e confluências emergentes. In: DENZIN, N.; LINCOLN, Y. (Org.). O Planejamento da pesquisa qualitativa: teorias e abordagens. Porto Alegre: Artmed, 2006. p. 169 - 192. 
MACHADO, T. et al. As práticas de desinvestimento pedagógico na Educação Física escolar. Movimento, Porto Alegre, v. 16, n. 2, p. 129-147, abr./jun. 2010.

MEASOR, L.; SIKES, P. Una visita a las historias de vida: ética y metodología de la historia de vida. In: GOODSON, I. (Org.). Historias de vida del profesorado. Barcelona: Octaedro 2004. p. 269 - 298.

NÓVOA, A.. Vidas de professores. Porto: Editora do Porto, 1995.

OLIVEIRA, V. F.. Narrativas e saberes docentes. In: OLIVEIRA, V. F. (Org.). Narrativas e saberes docentes. Ijuí: Educação Física. Unijuí, 2006a.

Implicar-se... implicando com professores: tentando produzir sentidos na investigação/formação. In: SOUZA, E. (Org.). Autobiografias, histórias de vida e formação: pesquisa e ensino. Porto Alegre: EDIPUCRS, 2006b. p. 47 - 57.

PÉREZ GÓMEZ, A. La cultura escolar en la sociedad neoliberal. Madrid: Morata, 1998.

SANCHO GIL, J.; HERNÁNDEZ, F. La formación del profesorado en tiempos de incertidumbre. Movimento, Porto Alegre, v. 10, n. 1, p. 9-39, jan./abr. 2004.

SANTINI, J.; MOLINA NETO, V.. A síndrome do esgotamento profissional em professores de educação física: um estudo na rede municipal de ensino de Porto Alegre. Revista Brasileira de Educação Física e Esporte, São Paulo, v. 19, n. 3, set. 2005. Disponível em: <http://www.revistasusp.sibi.usp.br/scielo.php?script= sci_arttext\&pid=S1807-55092005000300004\&Ing=pt\&nrm=iso >. Acesso: 3 out. 2011.

SANTOS, N.; BRACHT, V.; ALMEIDA, F.. Vida de Professores de Educação Física: o pessoal e o profissional no exercício da docência. Movimento, Porto Alegre, v. 15, n. 02, p. 141-165, abr./jun. 2009.

SENNETT, R. La corrosión del carácter: las consecuencias personales del trabajo en el nuevo capitalismo. Barcelona: Anagrama, 2003.

WITTIZORECKI, E. S.; MOLINA NETO, V. O trabalho docente dos professores de Educação Física na Rede Municipal de Ensino de Porto Alegre. Movimento, Porto Alegre, v. 11, n. 1, p. 47- 70, jan./abr. 2005.

Endereço para correspondência:

Rua Felizardo, ํㅜ 750

Bairro Jardim Botânico

Porto Alegre/RS. Brasil.

CEP 90690-200

Recebido em: 23.10.2011

Aprovado em: 27.03.2012

lovimento, Porto Alegre, v. 18, n. 01, p. 149-169, jan/mar de 2012. 
